\title{
University Students' Experiences of the Use of Mlearning as a Training Resource for the Acquisition of Biomechanical Knowledge
}

\author{
Ignacio López-Moranchel ${ }^{1,2}$, Evelia Franco ${ }^{1, *} \mathbb{C}$, Belén Urosa ${ }^{1} \oplus$, Patricia Maurelos-Castell ${ }^{3}$, Esther Martín-Íñigo ${ }^{1}$ \\ and Victoria Montes ${ }^{1}$ \\ 1 Faculty of Human and Social Sciences, Universidad Pontificia Comillas, 28049 Madrid, Spain; \\ ilmoranchel@comillas.edu or ignacio.lopez@uclm.es (I.L.-M.); burosa@comillas.edu (B.U.); \\ memartin@comillas.edu (E.M.-Í.); vmontes@comillas.edu (V.M.) \\ 2 GENUD Toledo Research Group, Universidad de Castilla-La Mancha, 45071 Toledo, Spain \\ 3 Hospital Universitario de Fuenlabrada, 28942 Fuenlabrada, Spain; patriciairene.maurelos@salud.madrid.org \\ * Correspondence: efalvarez@comillas.edu; Tel.: +34-91-734-39-50 (ext. 4437)
}

check for

updates

Citation: López-Moranchel, I.;

Franco, E.; Urosa, B.;

Maurelos-Castell, P.; Martín-Íñigo, E.;

Montes, V. University Students'

Experiences of the Use of Mlearning

as a Training Resource for the

Acquisition of Biomechanical

Knowledge. Educ. Sci. 2021, 11, 479.

https://doi.org/10.3390/

educsci11090479

Academic Editor: Mike Joy

Received: 1 August 2021

Accepted: 24 August 2021

Published: 30 August 2021

Publisher's Note: MDPI stays neutral with regard to jurisdictional claims in published maps and institutional affiliations.

Copyright: (c) 2021 by the authors. Licensee MDPI, Basel, Switzerland. This article is an open access article distributed under the terms and conditions of the Creative Commons Attribution (CC BY) license (https:/ / creativecommons.org/licenses/by/ $4.0 /)$.
Abstract: Mobile learning (mLearning) is now being increasingly used in university education, with positive impacts on the motivation and predisposition of students when learning. The aim of this study was to evaluate the impact of the use of mobile applications as a learning resource in applied biomechanics, with regard to attitudinal variables (interest, motivation, applicability and learning experience) and its efficacy in the learning of general physics contents. A quasi-experimental design was proposed, with the random assignment of participants to experimental and control groups, with the post-trial measurement of a sample of 76 university students studying Applied Biomechanics, who were given an ad-hoc questionnaire in order to evaluate attitudinal aspects, as well as a test of knowledge. With regard to attitudinal aspects, higher scores were observed among the group which used the applications as learning instruments (the experimental group) when evaluating their interest in biomechanics $(\mathrm{t}=2.79 ; p<0.05 ; \mathrm{d}=-0.641)$, the applicability of the applications in real life $(\mathrm{t}=7.34 ; p<0.001 ; \mathrm{d}=-1.687)$ and the general evaluation of the practical sessions $(\mathrm{t}=6.45$; $p<0.001 ; \mathrm{d}=-1.481)$. At the conceptual level, significant differences were observed in the contents worked on with the KinematicLab Jump® application. Our results show the positive effect of the use of applications on important attitudinal aspects in the learning of university students, without any relevant effect on the acquisition of conceptual learning.

Keywords: biomechanics; learning; mobile applications; motivation; sports sciences

\section{Introduction}

A considerable portion of education research in recent years has focussed, not only on identifying the most effective actions and situations to generate and consolidate learning, but also on what it is that incites the desire to learn. Different works have affirmed that motivation is a key factor in promoting learning, showing a positive correlation with academic performance, cognitive engagement and the learning experience itself [1-3]. Dweck and Leggett [4,5] suggested that motivation should be oriented towards certain competency or learning goals which permit the acquisition of new skills and mastery of the subject, suggesting that the achievement of those goals would require the use of active strategies which lead to profound, transferable learning and which make it possible to tackle new challenges, giving applicability to that learning [6,7]. That affirmation coincides with the image of university students put forward by the regulatory bodies of tertiary education: active participants in the learning process, who seek to enrich their perceptions through practical experiences inside and outside the classroom [8].

In recent years, different innovative pedagogical approaches have arisen in order to tackle the problems related to the academic performance and motivation of students, some 
of them based on the potential of games to redesign teaching-learning methodologies and processes (for example, gamification). In other cases, approaches have been promoted which take advantage of the development of information and communication technologies (ICTs), as well as the availability of internet connections. Along these lines, an increasing number of teachers make use of mobile technologies in their classes or outside them, placing them at the service of learning with multiple approaches within what is known as mobile learning (mobile learning), a resource which uses mobile communication technologies and offers students the ability to learn at any place and at any time. That definition is based on the proposal by O'Malley [9], which defines mLearning as: Any sort of learning that happens when the learner is not at a fixed, predetermined location, or learning that happens when the learner takes advantage of the learning opportunities offered by mobile technologies.

A number of concepts or trends related to mLearning have appeared, which are being promoted by different official bodies, such as BYOD (Bring Your Own Device), which proposes allowing students to use their own devices in classes, thereby achieving significant cost savings for those institutions, as well as saving time due to familiarity with the device [10]. The study of mLearning as a phenomenon is complex due to the need to analyse its many different contexts, social interactions, interactions of contents and the type of information, as well as their synergies [11,12], and therefore the authors frequently direct their research proposals towards the study of its conceptual bases [13], analysis of the theoretical frameworks and specific pedagogical designs [14-16], or the evaluation of conceptual understanding and analysis of the potentialities of mLearning with regard to learning [17-23].

MLearning is increasingly being used by teachers and students in health sciences at the advanced level, demonstrating efficacies which are equal to or greater than traditional methods, though, as some authors indicate, further research is necessary in order to assess its value $[24,25]$. However, in the context of advanced and university education in general, the evidence is rather scarce. Foreign languages are the subjects that have most frequently adopted mLearning [26,27], and there have also been initiatives specifically aimed at the use of mobile applications in the sphere of sciences [28] and specific subjects such as mathematics or chemistry [29,30]. In recent years, as the number of sensors incorporated into smartphones has increased, making it possible to use those devices as experimental tools, there have been multiple proposals for the use of telephones in some areas of physics, such as mechanics [31-35], optics [36], electromagnetism or radioactivity [37,38], to the extent that, in 2012, the official publication of the American Association of Physics Teachers (AAPT) incorporated a specific section on the experimental resources provided by mobile telephones. Other spaces for scientific exchange and communication, such as the blog of the British Journal of Sports Medicine (https:/ /blogs.bmj.com/bjsm/ (accessed on 14 July 2021)) have also included sections for the presentation of mobile applications for use in the context of sports sciences. In that regard, some studies suggest that the use of mobile applications in the educational context makes a positive contribution to students ${ }^{\prime}$ motivation, interest, curiosity about the contents and collaboration $[39,40]$, but there is a lack of quasi-experimental studies in specific spheres of knowledge.

Physical activity and sports sciences have also taken advantage of recent advances in the technology incorporated into smartphones and other portable devices, such as tablets or smart watches, which make it possible to measure a multitude of movement parameters. The vast majority of mobile telephones have a series of integrated sensors and functions: camera (or several cameras), chronometer, calculator, GPS, accelerometer, gyroscope, magnetometer, etc., which can be used as tools to measure and record data (text, audio, video, position, speed, etc.) that, moreover, can be exported or shared on the internet.

Research into kinetic or kinematic parameters based on the analysis of movement through video or photography is a resource that has frequently been used since the 1980s within the so-called Video-Based Laboratory, VBL [41], whose complexity has increased in line with the progress in technology (capture frequencies, editing possibilities, annotation, 
adjustment to human models, measurement, tracking of points, exporting files, etc.). The educational use of those laboratory videos has traditionally required the use, at least, of a camera and a laptop computer with software which makes analysis possible. Biomechanics, which studies biological systems using methods of mechanics, has made use of these movement analysis tools with the aim of achieving improvements in execution and performance techniques [42]. The incorporation of high-speed cameras into Smartphones and the need for low-cost functional evaluation tools (truly portable), together with the interest in Velocity-based Resistance Training (VBRT), have fostered the development of mobile applications which are useful to analyse kinematic training control variables [43-45] which permit video analysis via the mobile phone and the obtainment of training data from virtually any device and by any user.

Though there is evidence of the potential effects that these approaches may have on students' motivation, there are not so many studies that have analysed the effect of interventions based on these types of approaches on students' learning [46,47], and even fewer in the specific area of applied biomechanics. Therefore, experimental work to verify how those methodological approaches affect learning would be particularly relevant, given that the results of previous works have not proven to be entirely conclusive [48].

Some experiences prior to our study made us hypothesize about the possibility that our intervention through the use of mobile applications on learning caused positive changes, both at a conceptual and an attitudinal level, that we were not able to quantify; the need to verify the magnitude of this change, in addition to the absence of studies in the biomechanical context, were decisive elements in setting our objectives.

The aim of the present work is thus to evaluate the impact of the use of a series of mobile applications (five applications for mobile phones, together called KinematicLab) as a learning resource in biomechanics applied to physical activity, on a series of attitudinal variables (interest, motivation, applicability and learning experience). Secondly, the effect of these applications on students' learning of general conceptual contents about mechanical physics is also evaluated.

\section{Materials and Methods}

\subsection{Participants}

The sample of this study was composed of 76 students ( $79 \%$ male, $21 \%$ female), between the ages of 17 and $41(\mathrm{M}=19.36 ; \mathrm{SD}=2.915)$, studying in the field of Biomechanics Applied to Physical Activity and Sport, who were in the second year of a Bachelor's Degree in Physical Activity and Sports Sciences at two Spanish universities. Twenty one percent of the participants belonged to Universidad Pontificia Comillas, and 79\% to the Universidad de Castilla-La Mancha. Around 37\% of the participants accessed university from the Health Sciences Baccalaureate, nearly 33\% from the Social Sciences Baccalaureate, around 13\% from advanced studies in physical sports activities (TAFAD) and the remaining $17 \%$ from combinations of TAFAD with a subsequent Baccalaureate. Likewise, $23.7 \%$ of the sample had not studied Physics since the third year of obligatory secondary education, the last year in which that subject was mandatory, $3.6 \%$ since the 4 th year of secondary education and $26.3 \%$ since the 1 st year of the Baccalaureate, and only $17.1 \%$ had chosen it in the 2 nd year of the Baccalaureate.

\subsection{Instruments}

Attitudinal variables. An ad-hoc questionnaire was designed, composed of four questions, each one focussing on a specific aspect of interest in our research. Interest in biomechanics was assessed through the question "To what extent have the practical sessions contributed to increasing your interest in biomechanics?". Motivation with regard to the training activities was assessed by means of the question "What score would you give to the resolution of the activities of the practical sessions?". The applicability of the content of the training activity for professional life was evaluated by means of the question "To what extent do you think the practical sessions correspond to situations which are 
applicable in real professional life?". Finally, in order to assess their general satisfaction with the learning experience, they were asked "How would you evaluate your learning experience, in general, during the practical exercises?". These four questions were selected on the basis of actual concerns of the research team. The teacher who implemented the intervention had a large trajectory in the teaching of biomechanics and, according to his experience, undergraduate students often exhibited low levels of motivation or interest towards biomechanics. Thus, questions 1, 2 and 4 specifically aimed to address whether the proposed approach could have a positive effect on these outcomes. Furthermore, previous feedback given by undergraduate students belonging to the universities participating in the study had suggested that some training activities performed during the degree were not significant and applicable to their future professional settings. Question 3 was formulated to gain a better understanding of how the activities proposed in the experimental group were perceived by students as applicable in real professional life. All of those questions were answered on a Likert scale from 0 to 10.

The learning variables regarding the physics-related contents of the biomechanics course consisted of an objective test composed of 73 multiple choice questions with four options and only one correct answer. The questions were distributed across 28 dimensions corresponding to the different knowledge contents worked on with each one of the KinematicLab applications: Gonio 7 dimensions, Mov 5, Jump 6, Ball 6 and Susp 4, each one of which was represented by between one and four questions (see Table 1).

Table 1. Relation between the different applications, the parameters.

\begin{tabular}{|c|c|c|}
\hline App & Parameter Measured by the App & Contents (Dimensions of Knowledge Developed with Each App) \\
\hline KinematicLab Gonio (c) & Angles & $\begin{array}{ll}- & \text { Types of general movement } \\
- & \text { Types of joint movement } \\
\text { - } & \text { Axes and planes of movement } \\
- & \text { Centre of mass and range of joint movement } \\
\text { - } & \text { Angular measurement instruments } \\
\text { - } & \text { Concepts of degree and radian } \\
- & \text { Mechanical levers }\end{array}$ \\
\hline KinematicLab Mov $\subset$ & Angular velocity & $\begin{array}{ll}- & \text { Measurement of position and time (rectilinear movement) } \\
\text { - } & \text { Concept of average and instantaneous velocity } \\
\text { - } & \text { Importance of the frequency of sampling } \\
\text { - } & \text { Concept of acceleration and units of measurement } \\
\end{array}$ \\
\hline KinematicLab Jump @ & Height of a jump & $\begin{array}{ll}\text { - } & \text { Jump test } \\
\text { - } & \text { Vertical movement in gravitational field } \\
\text { - } & \text { Newton's 2nd Law } \\
\text { - } & \text { Dependency between the height and the speed of take-off } \\
\text { - } & \text { Measurement error and importance in measurement } \\
\text { - } & \text { Tools for evaluation of the vertical jump }\end{array}$ \\
\hline KinematicLab Ball @ & Reach of a throw & $\begin{array}{ll}\text { - } & \text { Horizontal and parabolic throw. Equations } \\
\text { - } & \text { Straight-line, uniformly-accelerated movement } \\
\text { - } & \text { Components of a force (dynamic) } \\
\text { - } & \text { Importance of the angle and height of the throw } \\
\text { - } & \text { Concept of Power } \\
\end{array}$ \\
\hline KinematicLab Susp @ & Forces & $\begin{array}{ll}\text { - } & \text { Conditions of equilibrium (Forces and Moments) } \\
\text { - } & \text { Frictional forces } \\
\text { - } & \text { Components of a force (static) } \\
\text { Centre of mass and distribution of the body mass }\end{array}$ \\
\hline
\end{tabular}

\subsection{Design and Procedure}

A quasi-experimental research design was formulated, with random assignment of the participants to the experimental and control groups and post-trial measurement (see Figure 1). It was decided to not take a pre-trial measurement of the variables in order to avoid the effects of reduction of internal validity caused by it. 


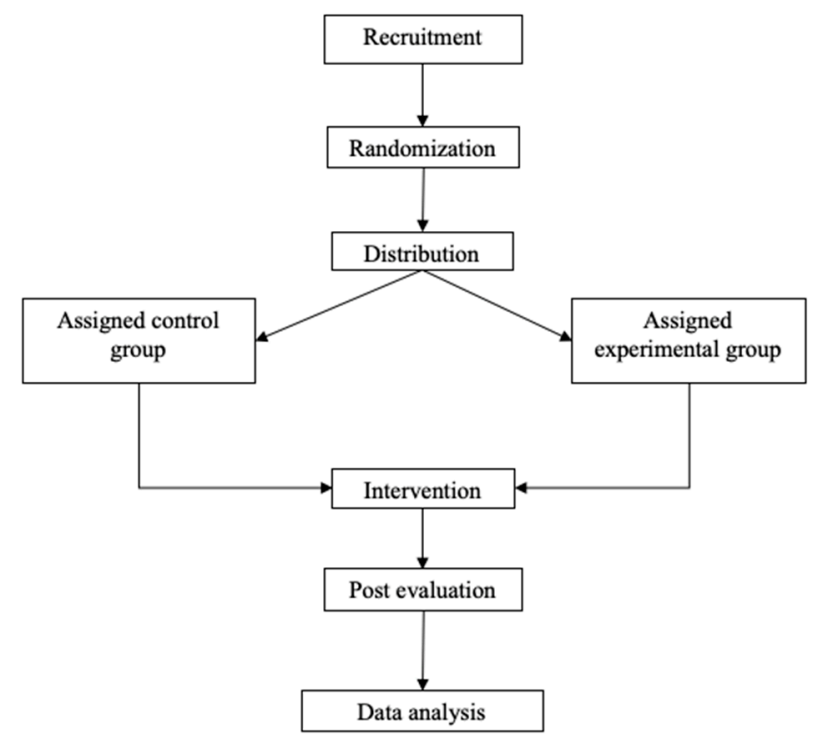

Figure 1. Design of the study.

The participants were assigned randomly in order to ensure the equivalence of the two groups, 40 students in each one. However, in the end, the control group was composed of 40 students, $52.6 \%$ of the sample, while the experimental group consisted of 36 students, $47.4 \%$, because four of the participants did not fulfil the evaluation criterion of attendance at $80 \%$ of the practical sessions. The relevant permissions and consents were obtained in accordance with the indications of the ethical principles and codes of conduct of the American Psychological Association (2002) and, both before the start of the intervention and after its completion, an external collaborator trained to that end administered the questionnaire previously described in the Instruments section.

\subsection{Description of the Intervention and the Kinematiclab Project}

KinematicLab is a series of five mobile applications (KinematicLab gonio (C), KinematicLab jump (C), KinematicLab Mov (C), KinematicLab Susp (c) and KinematicLab Ball (C), available free-of-charge for the IOS and Android operating systems, which make it possible to measure kinematic and kinetic parameters and which can be used as tools for the evaluation of physical parameters in biomechanics. Henceforth, the allusions to mobile applications in this study will refer to the applications of the KinematicLab project, unless otherwise specified.

The KinematicLab mobile applications make it possible to undertake a series of kinematic and kinetic measurements, and they provide results from the video recording of a gesture or movement, on which the operator of the mobile application carries out certain actions, such as the marking of positions or the selection of certain moments in the execution of the movement; those data are used by the algorithms of the mobile applications in order to calculate the parameters of interest in each one of them [49]. Table 1 sums up the main parameters which each mobile application measures and the knowledge contents (dimensions) related to it.

The intervention was carried out through a series of theoretical-practical sessions on our study group over the course of ten weeks between October and December, 2020, following the design shown in Figure 2. 


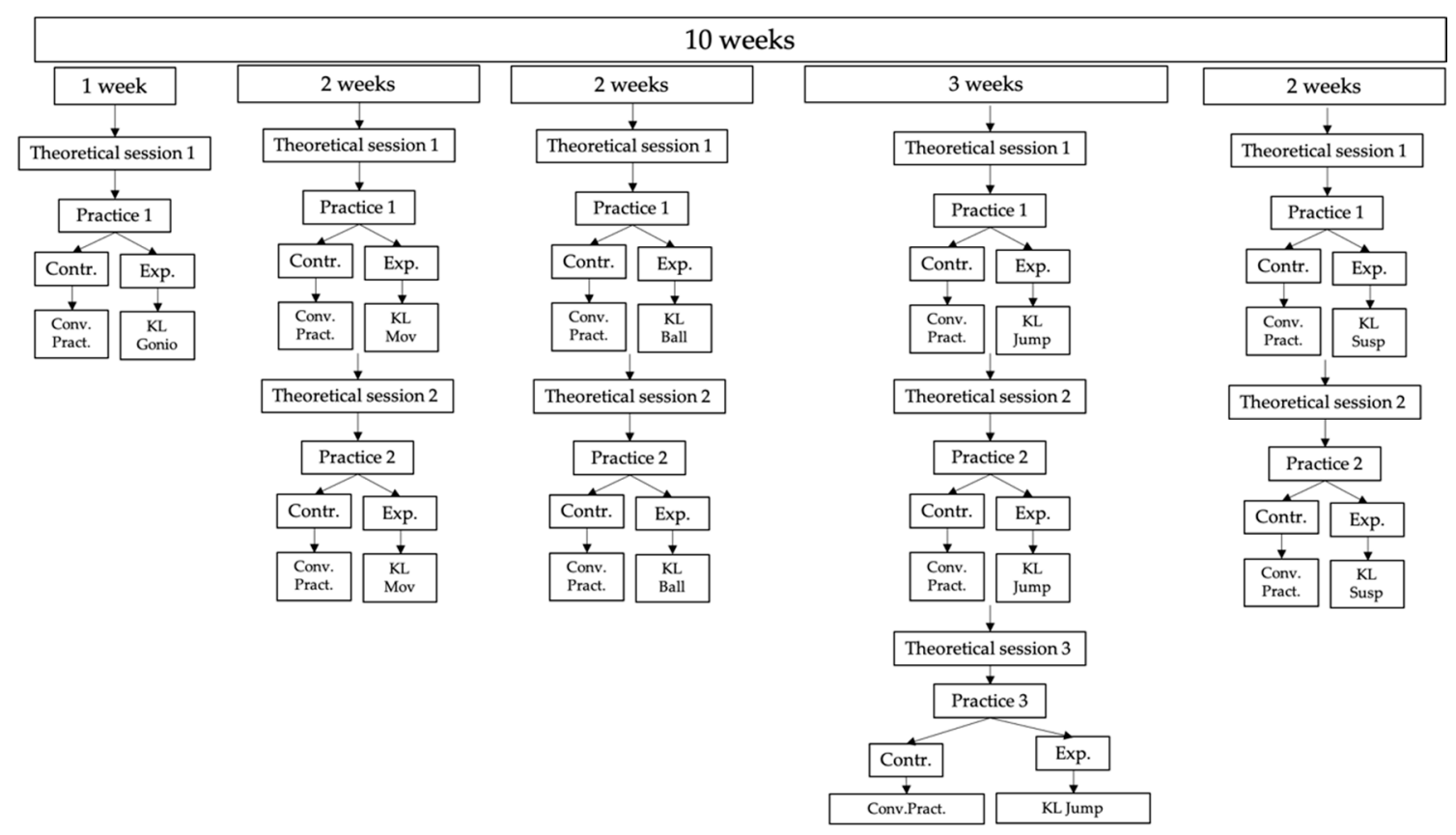

Figure 2. Design of the intervention (Note: Cont.: control group; Exp.: experimental group; Conv. Practice: conventional practice; KL: corresponding application of KinematicLab).

During the intervention, both groups (experimental and control) received two biomechanics classes each week: a theoretical session given to the entire group at the same time; and a different practical session for each group depending on whether they had been assigned to the experimental or control group. Both types of sessions, theoretical and practical, lasted $60 \mathrm{~min}$ and were given by the same teacher. The groups remained unchanged throughout the study. The students assigned to the control group spent the practical sessions resolving problems with traditional or conventional instruments and materials (spheres, inclined planes, axes, etc.) and based on the viewing of videos, whereas the students assigned to the experimental group spent the practical sessions taking measurements of body gestures or movements using apps and reproducing the development of the calculation algorithms of them on their laptop computers. Each one of the mobile applications was assigned a given number of practical sessions depending on the complexity of the contents (or dimensions) and the needs to do them.

\subsection{Analysis of Data}

First of all, the statistical descriptions of interest were calculated, and a correlational study between them was carried out (Table 2). Then, after having verified the normal distribution of the sample in the study variables by means of the Kolmogorov-Smirnov test $(p<0.05)$, a T test was carried out for independent samples in order to see whether there were any significant differences between the groups after the intervention. All the analyses were carried out using the SPSS 20.0 software. 
Table 2. Means (M), standard deviations (SD) and correlations between the attitudinal and learning variables.

\begin{tabular}{|c|c|c|c|c|c|c|c|c|c|c|c|c|}
\hline Variables & $\mathbf{M}$ & SD & 1 & 2 & 3 & 4 & 5 & 6 & 7 & 8 & 9 & 10 \\
\hline \multicolumn{13}{|l|}{ Attitudinal } \\
\hline 1. Interest & 7.64 & 1.27 & 1 & & & & & & & & & \\
\hline 2. Motivation & 7.88 & 1.37 & $0.712 * *$ & 1 & & & & & & & & \\
\hline 3. Applicability & 7.93 & 1.45 & $0.582 * *$ & $0.523 * *$ & 1 & & & & & & & \\
\hline 4. General Ev. & 7.68 & 1.12 & $0.770 * *$ & $0.654^{* *}$ & $0.612^{* *}$ & 1 & & & & & & \\
\hline \multicolumn{13}{|l|}{ Learning } \\
\hline 5. Test score & 6.40 & 1.09 & 0.111 & 0.109 & 0.157 & 0.126 & 1 & & & & & \\
\hline \multicolumn{13}{|c|}{ Average scores of each App } \\
\hline 6. KL Gonio & 0.72 & 0.12 & -0.088 & -0.099 & -0.160 & -0.070 & $0.591^{* *}$ & 1 & & & & \\
\hline 7. KL Mov & 0.72 & 0.12 & -0.040 & -0.041 & -0.045 & -0.092 & $0.769^{* *}$ & 0.733 ** & 1 & & & \\
\hline 8. KL Jump & 0.75 & 0.13 & 0.168 & 0.216 & $0.384^{* *}$ & $0.251 *$ & $0.754^{* *}$ & $0.329 * *$ & $0.452 * *$ & 1 & & \\
\hline 9. KL Ball & 0.71 & 0.07 & 0.049 & 0.222 & -0.041 & -0.013 & $0.568^{* *}$ & 0.306 ** & $0.405^{* *}$ & 0.241 * & 1 & \\
\hline 10. KL Susp & 0.78 & 0.11 & 0.069 & 0.037 & 0.031 & 0.058 & $0.823^{* *}$ & 0.540 ** & $0.641^{* *}$ & $0.512^{* *}$ & $0.383^{* *}$ & 1 \\
\hline
\end{tabular}

Note: Ev. = Evaluation; KL = KinematicLab; ${ }^{* *}$ The correlation is significant in level 0.01 (bilateral); ${ }^{*}$ The correlation is significant in level 0.05 (bilateral). 


\section{Results}

\subsection{Statistical Descriptions}

An analysis was undertaken of the statistical descriptions of the study variables, both attitudinal and of learning, whose results are shown in Table 2.

Likewise, when analysing the relations between the different variables (Table 2), it was observed that Actas de INTCESS 2020-7th International Conference on Education and Social Sciences there were significant correlations between the series of attitudinal variables and also between the series of learning variables, but not between the two series, with the exception of the contents worked on using the KinematicLab Jump@ application, which positively correlated with the attitudinal variables: applicability for professional life $\left(r=0.39^{* *}\right)$ and general evaluation of the learning experience $\left(r=0.25^{*}\right)$.

\subsection{Differences in Attitudinal Variables}

Subsequently, mean comparisons were undertaken through a series of $\mathrm{T}$ tests for independent samples, in order to analyse possible differences between the control group and the experimental group in the attitudinal variables of interest. As can be seen in Table 3, the scores of the experimental group were higher in interest in biomechanics $(\mathrm{t}=2.79 ; p<0.05 ; \mathrm{d}=-0.641)$, in the positive evaluation of the applicability of the mobile applications in real professional life $(\mathrm{t}=7.34 ; p<0.001 ; \mathrm{d}=-1.687)$ and in the general evaluation of the practical sessions through the use of the applications $(t=6.45 ; p<0.001 ; d=-1.481)$.

Table 3. Differences in means between the control group and the experimental group with regard to the attitudinal variables.

\begin{tabular}{|c|c|c|c|c|c|c|c|}
\hline & \multicolumn{2}{|c|}{$\begin{array}{c}\text { Control } \\
n=40\end{array}$} & \multicolumn{2}{|c|}{$\begin{array}{c}\text { Experimental } \\
\quad n=36\end{array}$} & \multirow[t]{2}{*}{$\mathbf{t}$} & \multirow[t]{2}{*}{ Sig } & \multirow[t]{2}{*}{ d } \\
\hline & $\mathbf{M}$ & SD & $\mathbf{M}$ & SD & & & \\
\hline Interest & 7.28 & 1.24 & 8.06 & 1.19 & 2.79 & 0.007 & -0.641 \\
\hline Motivation & 7.60 & 1.37 & 8.19 & 1.31 & 1.93 & 0.058 & -0.443 \\
\hline Applicability & 7.05 & 1.28 & 8.92 & 0.87 & 7.34 & 0.000 & -1.687 \\
\hline General Ev. & 7.05 & 0.90 & 8.39 & 0.90 & 6.45 & 0.000 & -1.481 \\
\hline
\end{tabular}

Note: KL $=$ KinematicLab. $p<0.05$.

\subsection{Differences in Learning Variables}

In contrast, as shown in Table 4 , the result of the student $\mathrm{T}$ test to compare the control and experimental groups in the general learning variable (total score of the test), revealed that there were no differences between the two groups $(\mathrm{t}=1.75 ; p=0.84 ; \mathrm{d}=-0.40)$.

Table 4. Differences in means between the control group and the experimental group with regard to learning variables.

\begin{tabular}{cccccccc}
\hline & \multicolumn{2}{c}{$\begin{array}{c}\text { Control } \\
\boldsymbol{n}=\mathbf{4 0}\end{array}$} & \multicolumn{2}{c}{$\begin{array}{c}\text { Experimental } \\
\boldsymbol{n}=\mathbf{3 6}\end{array}$} & $\mathbf{t}$ & Sig & $\mathbf{d}$ \\
\cline { 2 - 5 } & $\mathbf{M}$ & $\mathbf{S D}$ & $\mathbf{M}$ & $\mathbf{S D}$ & & & \\
\hline Test score & 6.19 & 0.85 & 6.63 & 1.28 & 1.75 & 0.084 & -0.403 \\
App Contents & & & & & & & \\
KL Gonio & 0.73 & 0.11 & 0.70 & 0.13 & -0.93 & 0.358 & 0.213 \\
KL Mov & 0.72 & 0.11 & 0.71 & 0.14 & -0.61 & 0.546 & 0.139 \\
KL Jump & 0.70 & 0.10 & 0.80 & 0.13 & 3.92 & 0.000 & -0.899 \\
KL Ball & 0.72 & 0.06 & 0.71 & 0.08 & -1.02 & 0.311 & 0.235 \\
KL Susp & 0.77 & 0.10 & 0.79 & 0.13 & 0.76 & 0.451 & -0.174 \\
\hline
\end{tabular}

Note: $\mathrm{KL}=$ KinematicLab. $p<0.05$.

However, on analysing those learning results in greater detail, it was observed that there were significant differences in favour of the experimental group with regard to the contents worked on with the KinematicLab Jump (C) application overall $(t=3.92 ; p<0.001 ; d=-0.899)$. 


\section{Discussion}

The first aim of this work was to evaluate the impact of the use of the KinematicLab mobile applications as a learning resource in the subject of biomechanics applied to physical activity with regard to a series of attitudinal variables (interest, motivation, applicability and learning experience). Our results showed significant differences in favour of the experimental group, in terms of both the increase in interest in biomechanics and the positive evaluation of the applicability of the mobile applications in real professional life and the general evaluation of the practical sessions using the mobile applications. Those results are in line with recent works which indicate that mLearning is not a transitory innovation, but rather a new characteristic of the teaching contexts which is here to stay [50].

It would be interesting to study in greater depth the mechanisms which explain the success of those proposals, in order to improve the motivation of the students. One of them could be the motivational incentive of using their own mobile phones in order to access knowledge [28], an aspect which has been noted for some years now [51].

Previous studies have provided information concerning the importance and benefits of generating real learning environments; at the same time, researchers have indicated the need to develop learning tools or mechanisms to help students to learn in authentic and complex scenarios $[52,53]$. In that regard, the results of our work would support the use of collaborative, integrated learning, in which theory and practice are closely interconnected and interact with each other; in fact, pedagogical proposals of this type are a resource which is increasingly used in education [54].

The second aim of this work was to verify the efficacy of the use of mobile applications in the learning of general biomechanics contents related to mechanics. Biomechanics studies the biological systems using the methods of mechanical physics. Traditionally, applied biomechanics is used to analyse movement in sports sciences and physiotherapy, and students consider it a complex discipline. As it requires kinematic and kinetic measurements, the learning process involves mastery of concepts of mechanics and practice in the use of instruments to measure gestures or actions (especially functional or sport-related ones), so it is beneficial to create educational contexts in which the situation and the instrument are available to the student in the way which most faithfully represents reality. Likewise, collaborative methodologies in which the students apply concepts to real situations appear to contribute positively to the achievement of the proposed learning objectives [55-58]. In this study, we did not find any significant differences between the experimental group and the control group in terms of their scores in the final conceptual test. In relation to that aspect, similar results were found in studies which evaluated the effect of the use of mobile applications on conceptual cognitive learning [56-58], so the evidence may suggest that the assimilation of concepts depends on multiple cognitive processes, not just the experience of using the mobile application. It should be taken into account that, in our case, the students of the control group received the same theoretical classes as the experimental group and also did practical sessions in relation to the concepts under study, and therefore the existence of considerable differences in those aspects would have meant a great effect of the use of mobile applications on learning.

On the other hand, though it is true that the positive contributions of learning through technological resources have been well documented in relation to a general educational context $[56,58]$, they have not been studied so much in more specific contexts, such as biomechanics, in which we did not find any works prior to this one.

Returning to the results of this work, we did find differences between the control and experimental groups in the results related to the dimensions worked on with KinematicLab Jump ( . That mobile application makes it possible to calculate the height and power of a vertical jump, in a simple way, from the recording of the jump and the selection of the moments of take-off and landing (frames) in the video. The jump, and more specifically the counter-movement vertical jump (CMJ), is a parameter of great interest in the evaluation of the power of the lower limbs, which shows a correlation with other performance variables $[45,59,60]$, and therefore the students were very interested in measuring it using 
the mobile application, which made it possible to make and measure a large number of jumps. Likewise, the rapid obtainment of measurements through the mobile application enabled the students themselves to compare the results obtained, take an interest in the execution, and thus make more efficient jumps as the sessions progressed. Finally, in the three practical sessions, the students in the experimental group were able to reproduce the calculation algorithm used by the mobile application, understanding the importance of each one of the conceptual variables which determine the height of a vertical jump. Those observations enable us to hypothesise that a simple measurement tool (in this case, the mobile application) can act as an incentive for more active and intense participation by the students, which positively impacts the acquisition of the concepts to be learnt.

This work has certain limitations which should be pointed out. First of all, the research sample was limited in number $(n=76)$, and therefore we recommend caution in the interpretation of the findings of the work. It would be interesting for future studies to consider how learning proposals based on the use of mobile applications influence the learning of university students of Physical Activity and Sports Sciences with larger samples. Likewise, the attitudinal variables were evaluated by means of an ad-hoc questionnaire which, though it was clear and easy to apply, provided limited information about the motivational aspects of the participants. It would be interesting to investigate, in future research projects, whether experiences of this kind affect different motivational aspects in different ways (intrinsic motivation, extrinsic motivation or demotivation), using validated instruments to measure those constructs.

\section{Conclusions}

In summary, this work reveals the positive effect of the use of mobile applications on important attitudinal aspects of university students in the learning of applied biomechanics. In addition, it should be noted that the learning achieved is not affected compared to traditional teaching methods.

Though the experiment using mobile applications does not appear to have led to substantial improvements in conceptual learning, the improvement in students' attitudes towards those contents is positive, and the greater interest shown by the students in the experimental group could favour future autonomous initiatives aimed at more in-depth learning of those contents.

In the same way, it should be noted that, in this study, free applications were used, which are readily-available to both teachers and students who want to make use of them. The results of this work therefore reinforce the potential of mobile applications as a useful teaching resource in university education.

Author Contributions: Introduction and Conceptualization, I.L.-M., E.F., P.M.-C.; methodology: V.M., B.U., E.F.; formal analysis and data curation: E.F., V.M., B.U., E.M.-I.; writing-original draft preparation: I.L.-M., E.F., V.M.; writing — review and editing: I.L.-M., E.F, V.M., B.U.; supervision: B.U., I.L.-M.; funding acquisition: I.L.-M.,P.M.-C. All authors have read and agreed to the published version of the manuscript.

Funding: This research was funded by Universidad Pontificia Comillas, grant number 03-1819.

Acknowledgments: Los autores agradecen a la Universidad Pontificia Comillas la financiación de este trabajo como proyecto de innovación docente. También agradecemos la colaboración prestada en este trabajo por los profesores Luis $\mathrm{M}^{\mathrm{a}}$ Alegre y Julian Alcazar de la Universida de Castilla-La Mancha.

Conflicts of Interest: The authors declare no conflict of interest.

\section{References}

1. Kusurkar, R.A.; Ten Cate, T.J.; Van Asperen, M.; Croiset, G. Motivation as an independent and a dependent variable in medical education: A review of the literature. Med. Teach. 2011, 33, 242-262. [CrossRef] [PubMed]

2. Rúiz Martín, H. ¿Cómo aprendemos? Una Aproximación Científica Al Aprendizaje y la Enseñanza, 2nd ed.; Graó: Barcelona, Spain, 2020; pp. 162-190. 
3. Wouters, A.; Croiset, G.; Galindo-Garre, F.; Kusurkar, R.A. Motivation of medical students: Selection by motivation or motivation by selection. BMC Med. Educ. 2016, 16, 37. [CrossRef]

4. Dweck, C.S. Motivational processes affecting learning. Am. Psychol. 1986, 41, 1040-1048. [CrossRef]

5. Dweck, C.S.; Legget, E.L. A social-cognitive approach to motivation and personality. Psysiol. Rev. 1988, 95, 256-273. [CrossRef]

6. Harackiewicz, J.M.; Barron, K.E.; Pintrich, P.R.; Elliot, A.J.; Thrash, T.M. Revision of achievement goal theory: Necessary and illuminating. J. Educ. Psychol. 2002, 94, 638-645. [CrossRef]

7. Barron, K.E.; Harackiewicz, J.M. Achievement goals and optimal motivation: Testing multiple goal models. J. Pers. Soc. Psychol. 2001, 80, 706-722. [CrossRef] [PubMed]

8. Silbrián, L.A. Expectativas de la formación universitaria desde la perspectiva de los estudiantes. Diá-Logos 2017, $19,25-37$.

9. O'Malley, C.; Vavoula, G.; Glew, J.; Taylor, J.; Sharples, M. WP4-Guidelines for Learning/Teaching/Tutoring in a Mobile Environment. 2005. Available online: https:/ / hal.archives-ouvertes.fr/hal-00696244/document (accessed on 16 July 2021).

10. INTEF. Diseñando el Aula del Futuro Bring Your Own Device (BYOD): Una Guía Para Directores y Docentes. 2016. Available online: https: / / cutt.ly/KyrT2U9 (accessed on 17 July 2021).

11. Danish, J.; Hmelo-Silver, C.E. On: Activities and Affordances for Mobile Learning. Comtemp. Educ. Psychol. 2019, 60, 101829. [CrossRef]

12. Taylor, J.; Sharples, M.; O’Malley, C.; Vavoula, G.; Waycott, J. Towards a task model for mobile learning: A dialectical approach. IJLT 2006, 2, 138. [CrossRef]

13. Crompton, H.; Burke, D.; Gregory, K.H.; Grabe, C. The use of mobile learning in science: A systematic review. J. Sci. Educ. Technol. 2016, 25, 149-160. [CrossRef]

14. Sharples, M.; Taylor, J.; Vavoula, G.A. Theory of learning for the mobile age. In The SAGE Handbook of E-Learning Research, 2nd ed.; Sage Publications: New York, NY, USA, 2016; pp. 63-81.

15. Laurillard, D. Pedagogical forms for mobile learning: Framing research questions. In Mobile Learning: Towards A Research Agenda; WLE Centre, IoE: London, UK, 2007; pp. 153-175.

16. Alrasheedi, M.; Capretz, L.F.; Raza, A. A Systematic Review of the Critical Factors for Success of Mobile Learning in Higher Education (University Students' Perspective). JECR 2015, 52, 257-276. [CrossRef]

17. Fabian, K.; Topping, K.J.; Barron, I.G. Mobile technology and mathematics: Effects on students' attitudes, engagement, and achievement. J. Comput. Educ. 2016, 3, 77-104. [CrossRef]

18. Moreira, F.; Santos Pereira, C.; Durão, N.; Ferreira, M.J. A comparative study about mobile learning in Iberian Peninsula Universities: Are professors ready? Telemat. Inform. 2018, 35, 4. [CrossRef]

19. Hirsh-Pasek, K.; Zosh, J.M.; Golinkoff, R.M.; Gray, J.H.; Robb, M.B.; Kaufman, J. Putting education in “Educational" apps: Lessons From the Science of Learning. Psycho. Sci. Public. Interest 2015, 16, 3-34. [CrossRef] [PubMed]

20. Baran, E. A Review of Research on Mobile Learning in Teacher Education. J. Educ. Techno. Soc. 2014, 17, 17-32. Available online: www.jstor.org/stable/jeductechsoci.17.4.17 (accessed on 17 July 2021).

21. UNESCO. Policy Guidelines for Mobile Learning. Available online: https://unesdoc.unesco.org/ark:/48223/pf0000219662 (accessed on 22 April 2020).

22. Wu, W.H.; Wu, Y.C.; Chen, C.Y.; Kao, H.Y.; Lin, C.H.; Huang, S.H. Review of trends from mobile learning studies: A meta-analysis. Comput. Educ. 2012, 59, 817-827. [CrossRef]

23. Cochrane, T.D. Exploring Mobile Learning Success Factors. Res. Learn. Technol. 2010, 18, 133-148. Available online: https: / /journal.alt.ac.uk/index.php/rlt/article/view/882 (accessed on 17 July 2021). [CrossRef]

24. Dunleavy, G.; Nikolaou, C.K.; Nifakos, S.; Atun, R.; Law, G.C.Y.; Car, L.T. Mobile Digital Education for Health Professions: Systematic Review and Meta-Analysis by the Digital Health Education Collaboration. J. Med. Internet Res. 2019, 21 , e12937. [CrossRef]

25. Guo, P.; Watts, K.; Wharrad, H. An integrative review of the impact of mobile technologies used by healthcare professionals to support education and practice. Nurs. Open. 2015, 3, 66-78. [CrossRef]

26. Crompton, H.; Burke, D. The use of mobile learning in higher education: A systematic review. Comput. Educ. 2018, 123, 53-64. [CrossRef]

27. Pimmer, C.; Mateescu, M.; Grohbiel, U. Mobile and ubiquitous learning in higher education settings: A systematic review of empirical studies. Comput. Hum. Behav. 2016, 63, 490-501. [CrossRef]

28. Zydney, J.M.; Warner, Z. Mobile Apps for Science Learning: Review of Research. Comput. Educ. 2016, 94, 1-17. [CrossRef]

29. Fabian, K.; Keith, J.T. Putting "mobile" into mathematics: Results of a randomized controlled trial. Comtemp. Educ. Psychol. 2019, 59, 101783 [CrossRef]

30. Dekhane, S.; Yin, T.M. Designing a Mobile Application for Conceptual Understanding: Integrating Learning Theory with Organic Chemistry Learning NeedS. IJMBL 2012, 4, 34-52. [CrossRef]

31. Chevrier, J.; Madani, L.; Ledenmat, S.; Bsiesy, A. Teaching classical mechanics using smartphones. Phys. Teach. 2013, 51, 376-377. [CrossRef]

32. Hochberg, K.; Grober, S.; Kuhn, J.; Muller, A. The spinning disc: Studying radial acceleration and its damping process with smartphone acceleration sensors. Phys. Edu. 2014, 49, 137-140. [CrossRef] 
33. Kuhn, J.; Vogt, P. Smartphones as Experimental Tools: Different Methods to Determine the Gravitational Acceleration in Classroom Physics by Using Everyday Devices. Eur. Phys. J. Plus 2013, 4, 16-27. Available online: https://eric.ed.gov/?id=EJ1052301 (accessed on 17 July 2021).

34. Shakur, A.; Sinatra, T. Angular momentum. Phys. Educ. 2013, 51, 564-565. [CrossRef]

35. Monteiro, M.; Cabeza, C.; Marti, A.C. Exploring phase space using smartphone acceleration and rotation sensors simultaneously. Eur. J. Phys. 2014, 35, 045013. [CrossRef]

36. Klein, P.; Hirth, M.; Grober, S.; Kuhn, J.; Muller, A. Classical experiments revisited: Smartphones and tablet PCs as experimental tools in acoustics and optics. Phys. Edu. 2014, 49, 412-418. [CrossRef]

37. Silva, N. Magnetic field sensor. Phys. Edu. 2012, 50, 372-373. [CrossRef]

38. Kuhn, J.; Molz, A.; Gröber, S.; Frübis, J. iRadioactivity-Possibilities and limitations for using smartphones and tablet PCs as radioactive counters. Phys. Edu. 2014, 52, 351-356. [CrossRef]

39. Hwang, G.J.; Wu, P.H. Applications, impacts and trends of mobile technology-enhanced learning: A review of 2008-2012 publications in selected SSCI journals. IJMLO 2014, 8, 83-95. [CrossRef]

40. Hochberg, K.; Kuhn, J.; Muller, A. Using Smartphones as Experimental Tools-Effects on Interest, Curiosity, and Learning in Physics Education. J. Sci. Educ. Technol. 2018, 27, 385-403. [CrossRef]

41. Koleza, E.; Pappas, J. The effect of motion analysis activities in a video-based laboratory in students' understanding of position, velocity and frames of reference. Int. J. Math. Educ. Sci. Technol. 2008, 39, 701-723. [CrossRef]

42. Payton, C.; Barlett, R. Biomechanical Evaluation of Movement in Sport and Exercise: The British Association of Sport and Exercise Science Guide; Carl, P., Roger, B., Eds.; Routledge: Oxford, UK, 2008.

43. Balsalobre-Fernández, C.; Kuzdub, M.; Poveda-Ortiz, P.; Campo-Vecino, J. Validity and Reliability of the PUSH Wearable Device to Measure Movement Velocity During the Back Squat Exercise. J. Strength Cond. Res. 2016, 30, 1968-1974. [CrossRef]

44. Balsalobre-Fernández, C.; Marchante, D.; Baz-Valle, E.; Alonso-Molero, I.; Jiménez, S.L.; Muñoz-López, M. Analysis of Wearable and Smartphone-Based Technologies for the Measurement of Barbell Velocity in Different Resistance Training Exercises. Font. Physiol. 2017, 8, 649. [CrossRef] [PubMed]

45. Balsalobre-Fernández, C.; Marchante, D.; Muñoz-López, M.; Jiménez, S.L. Validity and reliability of a novel iPhone app for the measurement of barbell velocity and 1RM on the bench-press exercise. J. Sport Sci. 2017, 36, 64-70. [CrossRef] [PubMed]

46. Alsawaier, R.S. The effect of gamification on motivation and engagement. J. Inf. Learn. Technol. 2018, 35, 56-79. [CrossRef]

47. Jeno, L.M.; Adachi, P.J.C.; Grytnes, J.A.; Vandvik, V.; Deci, E.L. The effects of m-learning on motivation, achievement and well-being: A Self-Determination Theory approach. Br. J. Educ. Technol. 2019, 50, 669-683. [CrossRef]

48. Huang, S.-Y.; Kuo, Y.H.; Chen, H.C. Applying digital escape rooms infused with science teaching in elementary school: Learning performance, learning motivation, and problem-solving ability. Think. Ski. Creat. 2020, 37, 681. [CrossRef]

49. López-Moranchel, I.; Alegre, L.M.; Maurelos-Castell, P.; Picó Pérez, V.; Ara, I. Theoretical Aspects for Calculating the Mobilized Load during Suspension Training through a Mobile Application. Appl. Sci. 2021, 11, 242. [CrossRef]

50. Criollo, C.S.; Guerrero-Arias, A.; Jaramillo-Alcázar, Á.; Luján-Mora, S. Mobile Learning Technologies for Education: Benefits and Pending Issues. Appl. Sci. 2021, 11, 4111. [CrossRef]

51. Looi, C.-K.; Wong, L.-H.; So, H.J.; Seow, P.; Toh, Y.; Chen, W. Anatomy of a mobilized lesson: Learning my way. Comput. Educ. 2009, 53, 1120-1132. [CrossRef]

52. Looi, C.K.; Seow, P.; Zhang, B.; So, H.J.; Chen, W.; Wong, L.H. Leveraging mobile technology for sustainable seamless learning: A research agenda. Br. J. Educ. Technol. 2010, 41, 154-169. [CrossRef]

53. Izharul, H.; Masood, A.; Rubina, H. Actas de INTCESS 2020. In Proceedings of the 7th International Conference on Education and Social Sciences, Dubai, United Arab Emirates, 20-22 January 2020.

54. Kettunen, J. Integrated Management of Higher Education: Summary of Management Approaches. Intech. Open. 2012, 11, 193-208. [CrossRef]

55. Chiang, T.H.C.; Yang, S.J.H.; Hwang, G.J. An augmented reality-based mobile learning system to improve students' learning achievements and motivations in natural science inquiry activities. J. Educ. Technol. Soc. 2014, 17, 352-365.

56. Hwang, G.J.; Chu, H.C.; Lin, Y.S.; Tsai, C.C. A knowledge acquisition approach to developing mindtools for organizing and sharing differentiating knowledge in a ubiquitous learning environment. Comput. Educ. 2011, 57, 1368-1377. [CrossRef]

57. Yang, J.C.; Lin, Y.L. Development and evaluation of an interactive mobile learning environment with Shared Display Groupware. J. Educ. Technol. Soc. 2010, 13, 195-207.

58. Hung, P.H.; Hwang, G.J.; Su, I.H.; Lin, I.H. A concept-map integrated dynamic assessment system for improving ecology observation competences in mobile learning activities. Turk. Online J. Educ. Technol. 2012, 11, 10-19.

59. Bosco, C.; Luhtanen, P.; Komi, P.V. A simple method for measurement of mechanical power in jumping. Eur. J. Appl. Physiol. 1983, 50, 273-282. [CrossRef] [PubMed]

60. Buchheit, M.; Spencer, M.; Ahmaidi, S. Reliability, usefulness, and validity of a repeated sprint and jump ability test. Int. J. Sports Physiol. Perform. 2010, 5, 3-10. [CrossRef] [PubMed] 